\title{
Scleroderma in childhood
}

\section{Report of 5 cases}

\author{
K. M. GOEL and R. A. SHANKS \\ From the Royal Hospital for Sick Children, Yorkhill, Glasgow
}

\begin{abstract}
Goel, K. M., and Shanks, R. A. (1974). Archives of Disease in Childhood, 49, 861. Scleroderma in childhood: report of 5 cases. Five cases of scleroderma in childhood have been reviewed. All presented with cutaneous complaints. Raynaud's phenomenon occurred in 2 and Sjögren's syndrome in one. A patient with linear scleroderma and hemiatrophy developed subcutaneous calcification 5 years after the onset of disease. Of the 5 patients reviewed, 2 have been clinically well for several years, while the disease is progressive in the remaining 3.

Because of the clinical and serological overlap, confusion is possible between dermatomyositis, scleroderma, juvenile rheumatoid arthritis, and systemic lupus erythematosus, particularly when these connective tissue disorders are so uncommon in children. It appears that scleroderma in children may be less severe than in adults and that systemic involvement is less common. The presence of Raynaud's phenomenon, antinuclear factor, lupus erythematosus (LE) cells, and a raised erythrocyte sedimentation rate indicate a poor prognosis.
\end{abstract}

The term progressive systemic sclerosis has been preferred to that of scleroderma for nearly 30 years, though manifestations of what appears to be the same disease may be neither systemic nor progressive. The relevance of this condition to paediatric medicine lies in the fact that it appears in childhood very rarely but presents problems of diagnosis and long-term management. Whenever the nature of a disease is not clearly understood there is likely to be difficulty in deciding whether or not a particular clinical condition can be assigned to it. This applies especially to the wide variety of clinical manifestations included under the term progressive systemic sclerosis. The purpose of this paper is to examine 5 cases which have been diagnosed as scleroderma or progressive systemic sclerosis in childhood, in the light of what is known of its natural history in adults, in the hope of shedding some light upon its management and prognosis. These cases have been briefly referred to in a review of uncommon connective tissue disorders in childhood, but otherwise there have been no reports in British paediatric publications as far as we can ascertain (Goel and Shanks, 1974).

Received 8 April 1974.
The skin manifestations of scleroderma are well known. The atrophy and tightening of the skin gives a characteristic appearance of pinched nose and pursed lips. The hands become shiny with tapered finger ends and restricted movement. The joints are involved, not only because of the constricting skin but also because of occasional concomitant arthritis. There may also be subcutaneous calcification and sometimes ulceration. Raynaud's phenomenon is not uncommon and may be severe with resultant gangrene. Extensive involvement of the gastrointestinal tract is possible, ranging from a mere widening of the periodontal membrane to involvement of the oesophagus, stomach, and intestine. Dysphagia is common and steatorrhoea also may occur, though neither have been seen in our small series. There may be cardiovascular, respiratory, and renal involvement, though these have not so far been prominent in children. As in other disorders of connective tissue, various serological and immunological abnormalities have been recorded. Hyper- $\gamma-$ globulinaemia is common with raised $\alpha_{2}$-globulins less frequent. The rheumatoid factor is present in some $40 \%$ of cases but in lower titre than in rheumatoid arthritis. Antinuclear factors are 


\begin{tabular}{|c|c|c|c|c|}
\hline Case no. & Sex & $\begin{array}{l}\text { Age at } \\
\text { onset } \\
\text { (yr) }\end{array}$ & $\begin{array}{l}\text { Duration } \\
\text { of follow } \\
\text { up }(y r)\end{array}$ & Skin changes \\
\hline 1 & $\mathbf{M}$ & $1 \frac{1}{4}$ & 14 & $\begin{array}{l}\text { Generalized sclerodermatous lesion } \\
\text { on face, thighs, legs, hands, feet } \\
\text { and abdomen }\end{array}$ \\
\hline 2 & $\mathrm{~F}$ & $10 \frac{1}{2}$ & 11 & $\begin{array}{l}\text { Skin tight and adherent to tissues } \vec{D} \\
\text { over hands, forearms, legs, and } \\
\text { lower one-third of thighs }\end{array}$ \\
\hline 3 & F & 2 & 5 & $\begin{array}{l}\text { Pigmented and depigmented patches } \\
\text { on left leg and arm; skin over lepp } \\
\text { extremity smooth and shiny with } \\
\text { areas of atrophy }\end{array}$ \\
\hline 4 & $\mathbf{F}$ & 48 & $1 \frac{1}{2}$ & $\begin{array}{l}\text { Skin tight over palm of left hand, } \\
\text { 4th and 5th fingers; depigmented } \\
\text { patches with telangiectasia on } \\
\text { abdomen and along iliac crest }\end{array}$ \\
\hline 5 & M & 9 & 1 & $\begin{array}{l}\text { Tightness of fingers and toes, skingo } \\
\text { of hands showed trophic changes } \\
\text { patch of telangiectasia on } \\
\text { abdomen }\end{array}$ \\
\hline
\end{tabular}

commonly found and the LE phenomenon occasionally. The course of the disease is variable but the prognosis is generally grave.

\section{Clinical material}

Five children were admitted to the Royal Hospital for Sick Children and Stobhill General Hospital, Glasgow, between December 1959 and January 1974. 3 were female and 2 male. The age at onset of disease ranged from 2 years to $10 \frac{1}{2}$ years with a mean of $5 \frac{1}{2}$ years. The duration of observation ranged from 1 to 14 years. All children were examined clinically, radiologically, and immunologically and the main features are summarized in Tables I and II. In all the diagnosis was confirmed by skin biopsy which showed generalized atrophy of the dermis with irregularity of the collagen bundles.

Case 1. A boy, aged 1 year 3 months, was admitted in December 1959. At the age of 9 months he was noted to have swelling of the right side of his face and induration of the thighs. He had no constitutional symptoms. 6 months later he developed hardening of skin and subcutaneous tissue, most marked over his face, arms, hands, thighs, legs, feet, and sacroiliac region. The findings on physical examination were essentially normal except for these cutaneous features. All the lesions of scleroderma had completely disappeared by April 1963. Throughout the period of observation over the past 14 years he has remained perfectly well. A coincidental finding in this case was phenylketonuria and the child is mentally retarded.

Case 2. A girl, aged $10 \frac{1}{2}$ years, was admitted in November 1962 with a history of pain and swelling of both knees and pain in both her calves for the previous 6 weeks. On examination she had marked muscle wasting and there was a feeling of firmness of the muscles of the hands, forearms, thighs, and legs. The overlying skin was adherent to the subcutaneous tissues. The physical findings were otherwise normal. She was seen for review in January 1963 when she was symptom free and her skin had returned to normal. Over the past 11 years the disease process has been quiescent and she has been functionally normal.

Case 3. A 2-year-old girl was first seen in October 1967 with areas of pigmentation and depigmentation mainly affecting the left side of the body. The skin over the left arm and leg had a glazed appearance with areas of atrophy and linear thickening. She also had soft tissue swelling around the knees and ankles. The remainder of the physical examination was negative. 9 months later on re-evaluation her left leg from the toes to the knee showed marked sclerodermatous changes; similar changes were also seen on the lateral aspect of the left thigh: the face was not involved. The clinical picture was now that of linear scleroderma. Over the past 5 years she has developed marked atrophy of the left lower limb (Fig. 1) with $5 \mathrm{~cm}$ of shortening of the left tibia and fibula (Fig. 2). She also developed soft tissue calcification just below the midshaft of her left tibia and fibula and in soft tissues of the left foot. As she walks with a limp, a suitable shoe with 2.5 raise has been prescribed. The disease in this child continues to follow a slow but progressive course. There was radiological evidence of oesophageal involvement but there are as yet no symptoms. At no time was drug therapy employed in this case.

Case 4. A girl, aged $4 \frac{3}{4}$ years, was admitted in September 1972 with a history of Raynaud's phenomenon involving the $3 \mathrm{rd}, 4 \mathrm{th}$, and 5 th fingers of the left hand of 3 months' duration. 2 months later her mother noticed that the skin had become hard and shiny 
I clinical findings

\begin{tabular}{|c|c|c|}
\hline $\begin{array}{c}\text { Raynaud's } \\
\text { phenomenon }\end{array}$ & Other systems & Current status and associated features \\
\hline -ve & - & Quiescent over past 11 years \\
\hline -ve & Arthritis & Quiescent over past 11 years \\
\hline - ve & $\begin{array}{l}\text { Arthritis, } \\
\text { gastro-oesophageal } \\
\text { reflux }\end{array}$ & $\begin{array}{l}\text { Slowly progressive linear scleroderma } \\
\text { with hemiatrophy; marked atrophy of }\end{array}$ \\
\hline +ve & Arthritis & $\begin{array}{l}\text { Slowly progressive, atrophy of left upper } \\
\text { arm }\end{array}$ \\
\hline + ve & $\begin{array}{l}\text { Arthritis, } \\
\text { pericarditis }\end{array}$ & Slowly progressive, Sjögren's syndrome \\
\hline
\end{tabular}

and the fingers had become fixed in a flexed position. At the same time it was noted that depigmented patches with telangiectasia had developed on the abdominal wall and right thigh. She also complained of fatigability, loss of appetite, and pain in her calves on walking. 6 months later she developed atrophy of her left arm. Though the arms were of equal length there was considerable loss of subcutaneous tissue in the medial aspect of the left upper arm. There were no other positive findings on examination. She is unable to clench her left hand because of contracture deformities of the 4 th and 5 th fingers.

Case 5. A 9-year-old boy was admitted in June 1972 with a history of Raynaud's phenomenon of the fingers for about 2 years. There was no real history of joint involvement until May 1972 when he developed arthritis

TABLE II

Summary of laboratory findings

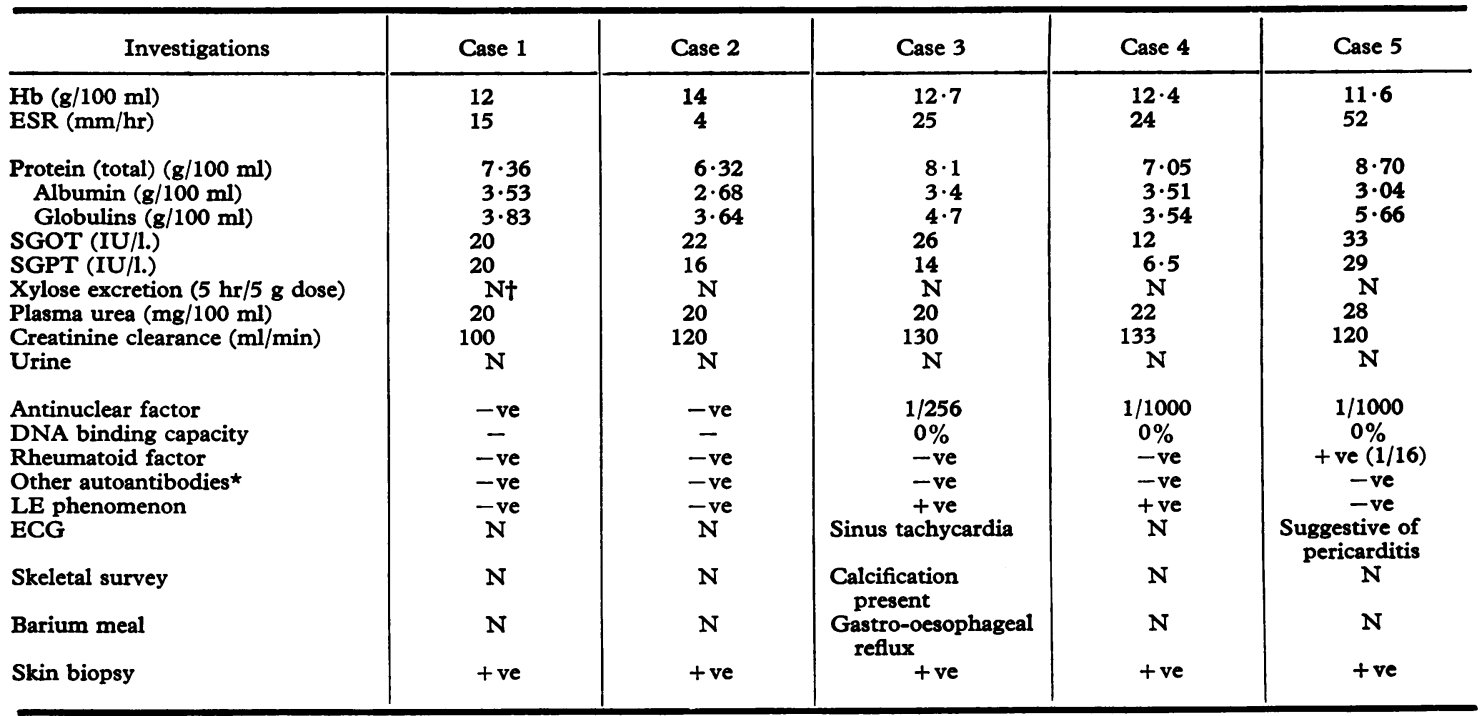

^Smooth muscle antibody, salivary duct antibody, adrenal cortex antibody, gastric parietal cell antibody, mitochondrial antibody, thyroglobulin antibody, and thyroid microsomal antibody.

tN (no abnormality detected), normal. 


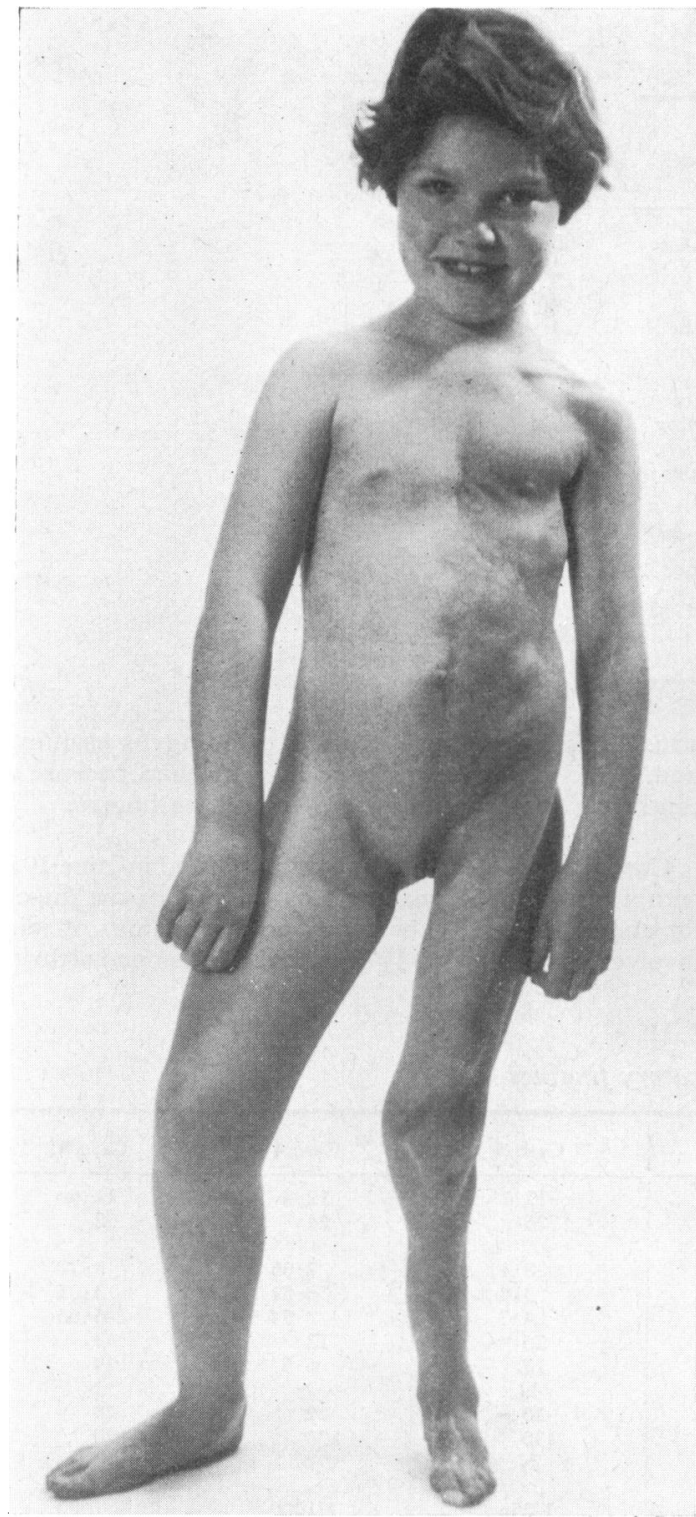

Fig. 1.-Case 3. Linear scleroderma with extensive involvement of the left side of the body and left leg in a 7-year-old girl.

mainly affecting the ankles and hip joints and was initially diagnosed as juvenile rheumatoid arthritis. On examination there was tenderness of wrists, right knee, both ankles, and all metacarpophalangeal and proximal interphalangeal joints. There was tightness of the skin of fingers and toes. The skin of his hands showed trophic changes and there was a patch of telangiectasia on

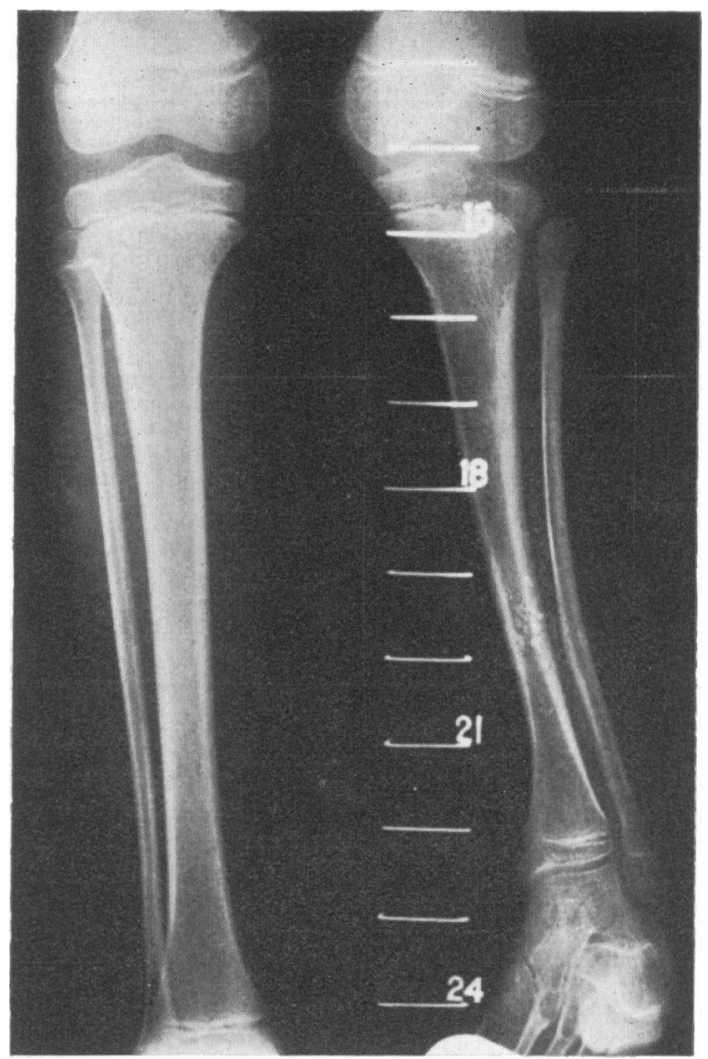

Fig. 2.-Case 3. Showing shortening of tibia and fibula and calcification in patient with linear scleroderma.

his abdomen. The physical findings were essentially normal except for those related to the skin and joints. In July 1972 he developed left parotid enlargement. Secretory sialography showed punctate and globular sialectasis consistent with a diagnosis of Sjögren's syndrome. In December 1972 he suddenly developed acute pericarditis and responded dramatically to corticosteroid therapy (prednisolone $40 \mathrm{mg}$ daily). The vasospastic phenomena had continued to increase in severity. A digital arteriogram of this child disclosed a considerable narrowing of the radial arteries and palmar arches (Fig. 3). The disease process in this patient is slowly progressive.

\section{Discussion}

Although scleroderma was described long ago, its aetiology still remains obscure, its course unpredictable, and its therapy of little benefit (Tuffanelli and Winkelmann, 1961). Some clinicians feel the prognosis may be relatively benign in childhood (Jaffe and Winkelmann, 1961), but others regard it as a serious illness in this age group (Kass, Hanson, and Patrick, 1966). 


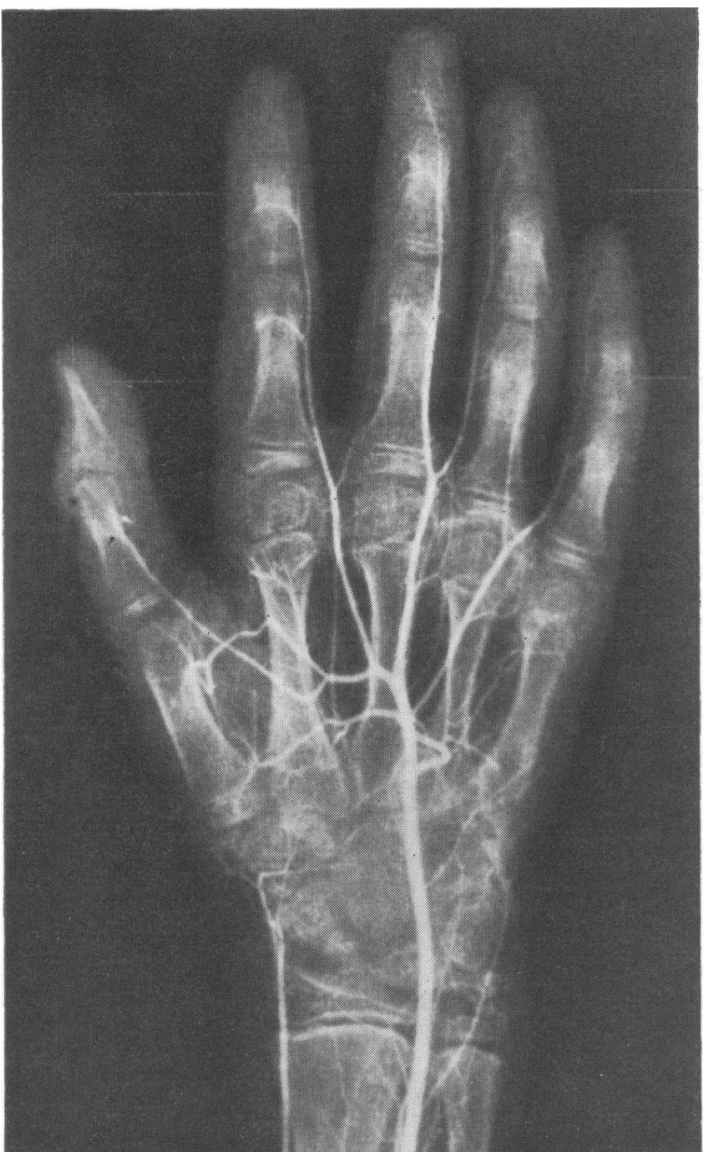

FIG. 3.-Case 5. Digital arteriogram illustrating considerable narrowing of radial artery. Note the thumb and the fingers receive only one normal digital artery each.

The onset of disease in our 5 patients was characterized by cutaneous complaints associated with joint symptoms in 3 and Raynaud's phenomenon in 2 (Cases 4 and 5). The joints mainly involved were knees, ankles, metacarpophalangeal and interphalangeal joints. Rodnan (1962) reported that frank polyarthritis or arthralgia is an early or a presenting feature in about $40 \%$ of patients with this disease: confusion with rheumatoid arthritis is possible and synovial biopsy may be necessary to make the diagnosis. The distinction between scleroderma and dermatomyositis may also be difficult and may require both skin and muscle biopsy for its elucidation (Goel and Shanks, 1974). Raynaud's phenomenon is supposed to be quite frequent and may precede the clinically recognizable disease by many years-as many as 12 to 16 (DeTakats and Fowler, 1962). In Case 5 the interval between the Raynaud's phenomenon and the diagnosis was 2 years. When severe digital ischaemia is present as in Case 5, vasodilator drugs are valueless, though maintaining the temperatures of the digits by lined gloves in cold weather and the protection of hands from trauma is of some benefit (Sackner, 1966). Sjögren's syndrome may be associated as in Case 5. This is a benign disease and there is no specific therapy (Shearn, 1960; Bloch et al., 1965).

Muller, Brunsting, and Winkelmann (1959) stated that calcinosis is a late sequel of scleroderma as it occurs on average about 11 years after the onset of disease and suggests a more favourable prognosis. Of the 3 patients followed up for 14, 11, and 5 years, subcutaneous calcification developed only in one patient (Case 3), 5 years after the onset of disease. The association between subcutaneous calcification and scleroderma has been known as ThibiergeWeissenbach syndrome (Leinwand, Duryee, and Richter, 1954).

With regard to the laboratory features, the cases of scleroderma with antinuclear antibodies (Cases 3, 4, and 5) and a positive LE cell phenomenon (Cases 3 and 4) may lead to difficulties in diagnosis (Table II). They may be misdiagnosed as cases of systemic lupus erythematosus (SLE). However, the presence of antinuclear factor in general is not diagnostic of any one disease; neither is the presence of LE cells nor a positive rheumatoid factor. Our patients did not have antibodies to native DNA in their sera which excludes the diagnosis of SLE. Furthermore, the direct immunofluorescent tests on the patients' normal and involved skin were negative for SLE. A positive antinuclear factor has been reported in 30 to $78 \%$, a positive rheumatoid factor in $30 \%$, and positive LE preparations in $6 \%$ of patients with scleroderma (Rothfield and Rodnan, 1968; Sackner, 1966). The course of scleroderma is extremely variable and frequent relapses and remissions both in cutaneous and visceral manifestations may occur. Kass et al. (1966) reported that in childhood it can follow a progressive course as rapidly fatal as in adult life.

None of our patients on detailed investigations showed evidence of abnormality of pulmonary, cardiac, gastrointestinal, or renal function except Case 3 who showed radiological evidence of oesophageal involvement and Case 5 who developed acute pericarditis. The oesophagus is probably the most common extracutaneous site of sclerotic changes in scleroderma (Tuffanelli, 1970). Atkinson and Summerling (1966) reported that by means of a cineradiography and manometry, loss of 
oesophageal peristalsis could often be shown before symptoms appeared. Pericarditis and pericardial effusion leading to cardiac tamponade have been appreciated with increasing frequency (Oram and Stokes, 1961). These authors also report that earliest cardiac manifestations of scleroderma are found in the ECG and they recommend a regular search for evidence of visceral involvement as involvement can occur even after many years. These findings support the view that systemic involvement is less common in childhood (Hanson and Kornreich, 1967).

Although the number of cases is small, it appears that the disease in childhood may improve spontaneously and the skin return to normal without any visceral involvement as observed in Cases 1 and 2. The disease in these 2 children followed a slow and benign course and has been quiescent over the past 11 years. Our Case 3 with linear scleroderma has developed over the past 5 years a marked atrophy of the left lower limb. The disease process in this patient is slowly progressive and the longterm prognosis seems to be poor. Similarly, the prognosis in Case 4 with atrophy of left arm and in Case 5 with involvement of pericardium, marked vasospastic phenomena, and Sjögren's syndrome seems to be poor. In both children with Raynaud's phenomenon there is an impending danger of gangrene. In Case 4, unlike Case 3, there has been no underlying bony atrophy.

Although it is difficult to judge prognosis early in the course of the illness, the presence of Raynaud's phenomenon, antinuclear factor, LE cells, and raised ESR (Cases 3, 4, and 5) is probably indicative of a poor prognosis.
We are grateful to our colleagues in the Royal Hospital for Sick Children and the Paediatric Department, Stobhill General Hospital, Glasgow, for allowing us to study patients under their care.

\section{REFERENCES}

Atkinson, M., and Summerling, M. D. (1966). Oesophageal changes in systemic sclerosis. Gut, 7, 402.

Bloch, K. J., Buchanan, W. W., Wohl, M. J., and Bunim, J. J. (1965). Sjögren's syndrome. A clinical, pathological, and serological study of sixty-two cases. Medicine, 44, 187.

DeTakats, G., and Fowler, E. F. (1962). Raynaud's phenomenon. fournal of the American Medical Association, 179, 1.

Goel, K. M., and Shanks, R. A. (1974). Uncommon connective tissue disorders in childhood. Scottish Medical fournal, 19, 65.

Hanson, V., and Kornreich, H. (1967). Systemic rheumatic disorders (collagen disease) in childhood: lupus erythematosus, anaphylactoid purpura, dermatomyositis and scleroderma. Bulletin on the Rheumatic Diseases, 17, 435.

Jaffe, M. O., and Winkelmann, R. K. (1961). Generalized scleroderma in children. Archives of Dermatology, 83, 402.

Kass, H., Hanson, V., and Patrick, J. (1966). Scleroderma in childhood. Fournal of Pediatrics, 68, 243.

Leinwand, I., Duryee, A. W., and Richter, M. N. (1954). Scleroderma. Annals of Internal Medicine, 41, 1003.

Muller, S. A., Brunsting, L. A., and Winkelmann, R. K. (1959). Calcinosis cutis; its relationship to scleroderma. Archives of Dermatology, 80, 15.

Oram, S., and Stokes, W. (1961). The heart in scleroderma. British Heart fournal, 23, 243.

Rodnan, G. P. (1962). The nature of joint involvement in progressive systemic sclerosis (diffuse scleroderma). Clinical study and pathologic examination of synovium in twenty-nine patients. Annals of Internal Medicine, 56, 422.

Rothfield, N. F., and Rodnan, G. P. (1968). Serum antinuclear antibodies in progressive systemic sclerosis (scleroderma). Arthritis and Rheumatism, 11, 607.

Sackner, M. A. (1966). Scleroderma, p. 27. Grune and Stratton, New York and London.

Shearn, M. A. (1960). Sjögren's syndrome in association with scleroderma. Annals of Internal Medicine, 52, 1352.

Tuffanelli, D. L. (1970). Scleroderma. In Current Therapy, p. 602. Ed. by H. F. Conn. Saunders, Philadelphia.

Tuffanelli, D. L., and Winkelmann, R. K. (1961). Systemic scleroderma. Archives of Dermatology, 84, 359.

Correspondence to Dr. K. M. Goel, Royal Hospital for Sick Children, Yorkhill, Glasgow G3 8SJ. 